\title{
Comparative study of X-ray computerised tomography and conventional $X$-ray methods in diagnosis of swimbladder infection in eels caused by Anguillicola crassus
}

\author{
C. Székely ${ }^{1, *}$, K. Molnár ${ }^{1}$, T. Müller ${ }^{2}$, A. Szabó ${ }^{3}$, R. Romvári ${ }^{3}$, C. Hancz ${ }^{4}$, M. Bercsényi ${ }^{2}$ \\ ${ }^{1}$ Veterinary Medical Research Institute, Hungarian Academy of Sciences, 1143 Budapest. Hungária krt. 21, Hungary \\ ${ }^{2}$ Department of Zoology, Georgikon Faculty of Agriculture, University of Veszprém, 8360 Keszthely Deák F. u. 16, Hungary \\ ${ }^{3}$ Institute of Diagnostic Imaging and Radiation Therapy, and ${ }^{4}$ Department of Fish and Pet Animal Breeding, \\ Faculty of Animal Sciences, University of Kaposvár, 7400 Kaposvár, Guba S. u. 40, Hungary
}

\begin{abstract}
To date, swimbladder lesions due to Anguillicola crassus infection of the European eel Anguilla anguilla have so far been studied only by conventional X-ray methods. This is the first study to report the use of computerised tomography (CT) for studying lesions induced by anguillicolosis. Of 50 eels caught by electrofishery from Lake Balaton, Hungary, in autumn 2002 and pre-selected by a conventional X-ray method, 22 specimens were examined with a Siemens Somatom Plus S40 spiral CT scanner. Tomograms, radiographs and photographs of 5 of these, showing anguillicolosis-induced swimbladder lesions of varying severity, are presented. Computerised tomograms provide information on the inner structure, air content and wall thickness of the swimbladder as well as on the number of worms it contains. When the swimbladder is not severely affected or not completely filled with worms, computerised tomography provides adequate data on the shape of the swimbladder, thickness of the swimbladder wall and the location of worms in the lumen. However, in more severe cases, i.e. when the swimbladder is tightly packed with worms or contains no air as a result of wallthickening, this method fails to determine the number and location of helminths or the thickness of the swimbladder wall.
\end{abstract}

KEY WORDS: European eel · Anguillicola crassus - Swimbladder infection · Pathological changes · $\mathrm{X}$-ray computerised tomography $\cdot$ Conventional X-ray

\section{INTRODUCTION}

Swimbladder infection by Anguillicola crassus is a well-studied, important disease of Anguilla anguilla in Europe. The parasite was presumably introduced into Europe with Japanese eels Anguilla japonica in the early 1980s and soon caused widespread infection over the European range of $A$. anguilla. It has been reported from Europe and the Mediterranean region of Africa in more than 140 studies. A detailed review of its spread, anatomic features and developmental characteristics of the parasite was published by Moravec
(1992). Abundant data on the pathological changes caused by adult worms parasitic in the lumen of the swimbladder and by larvae migrating to the swimbladder wall were provided by van Banning \& Haenen (1990), Molnár et al. (1993), Molnár (1994) and Würtz \& Taraschewski (2000). Soon after its first detection in Hungary in 1990 (Székely et al. 1991), A. crassus caused mass mortality of eel in Lake Balaton (Molnár et al. 1991, 1993). Similar mortalities were observed in the Czech Republic by Barus (1995). Molnár (1993) reported that $A$. crassus infection increasingly impairs the natural resistance of eels with increasing number 
of worms colonising the swimbladder and consequent increasing thickening of the swimbladder wall; and that severely affected fish die if the oxygen content of the water decreases. The correlation between infection and viability was also demonstrated by the experiment of Sprengel \& Lüchtenberg (1991), who demonstrated that the swimming speed of infected fish decreased in proportion to the severity of infection. Barus \& Prokes (1996) found that infection also influenced the length/ weight relationship of $A$. anguilla.

Beregi et al. $(1998,2001)$ reported that swimbladder changes, which had earlier been detectable only after dissections, could be revealed by radiodiagnostic methods which provided reliable data on the number of worms, the amount of air in the swimbladder and, indirectly, on the thickness of the swimbladder wall. The great potential of radiodiagnostic methods in fish medicine was suggested by Böttcher \& Böttcher (2000). Computerised tomography as a diagnostic method is widely used in human and veterinary medicine, providing useful data on the wall thickness of organs such as the urinary bladder and the gallbladder, as well as on the size and shape of stones or tumours in those organs (Laato et al. 2001, Gore et al. 2002, Pavlidis et al. 2002, Rickes \& Ocran 2002). In the field of parasitic infection, computerised tomography has proved suitable for the diagnosis of hydatid infections and for checking the efficacy of therapy (Minguetti \& Ferreira 1983, Liu et al. 1993, Ramos et al. 2001, Kilani \& El Hammami 2002). In relation to fish, the technique is used primarily for the detection of fish bones that pose a problem in human nutrition (Palme et al. 1999), but there are some data on its use in diagnosing skeletal and swimbladder abnormalities of ornamental fish also (Love \& Lewbart 1997, Bakal et al. 1998, Garland et al. 2002, Weisse et al. 2002).

The above reports prompted us to study the value of computerised tomography (a method widely used for visualising the contours and other features of organs) as an aid in the diagnosis of Anguillicola crassus infection.

This paper reports computer tomographic studies conducted on the swimbladders of Anguilla anguilla affected by Anguillicola crassus infection of varying severity pre-selected by a radiodiagnostic method.

\section{MATERIALS AND METHODS}

Anguilla anguilla used in this study were 60 to $75 \mathrm{~cm}$ long and at least $12 \mathrm{yr}$ old. They were collected from Lake Balaton, in the region of Keszthely and Tihany, Hungary, by electrofishery on several occasions between April and October 2002. The eels were transported to the laboratory in oxygen-filled foil bags, and maintained in concrete basins or plastic tanks supplied with flow-through water for a few days until examination. At each sampling, about 10 to 20 eels were killed and dissected to determine the proportions of eels with thickened or with relatively thin swimbladder walls, as well as the number of adult and larval Anguillicola crassus nematodes in their swimbladders. If worminfected eels with thin swimbladder walls, worm-free eels with thin swimbladder walls or/and eels with thickened swimbladder walls were found among the eels during these preliminary dissections, then the remaining eels in the sample were X-rayed using the method of Beregi et al. (1998). 50 eels were X-rayed prior to examination by computerised tomography; of these, we selected 22 eels on the basis of the swimbladder status visible on the radiographs. On 2 such occasions (9 September 2002 and 29 November 2002), 14 and 8 eels were selected, respectively. These eels were then placed individually into oxygen-filled foil bags and transported to the University of Kaposvár for tomographic examination. The eels were scanned in vivo with a Siemens Somatom Plus S40 spiral CT scanner at the Institute of Diagnostic Imaging and Radiation Therapy. After narcosis (essential oil of cloves, Syzygium aromaticum) the eels were placed in a plastic holder and covered with a wet towel. The topogram clearly revealed the position and shape of the swimbladder. Depending on the swimbladder size, 12 to 15 cross section scans were taken, totally covering the whole swimbladder. Characteristic settings were: slice thickness $=5 \mathrm{~mm}$, zoom factor $=15.1$, no gaps between consecutive slices.

A post-processing software was used to evaluate the CT images. The visualisation window was set to show only the bladder wall (window width $=200$ Hounsfield units, window centre $=60 \mathrm{Hu}$ ); All surrounding tissues were excluded where possible. The thickness of the swimbladder wall was measured at 3 anatomical locations $(15,30$ and $40 \mathrm{~mm}$ caudal of the first scan across the bladder). Wall thickness was recorded at 3 points (caudal side $; 1 \times 90^{\circ}$ clockwise; $1 \times 90^{\circ}$ counterclockwise on the swimbladder wall) in all 3 images. All 3 data sets were combined, and the eels were ranked according to the wall-thickness data.

After the CT examination, the eels were again anaesthetised by adding a few drops of oil of cloves to the water, then killed and their swimbladder removed. Prior to and after lengthwise incision of the swimbladders, they were photographed with a Fuji Finepix 2800 type digital camera. The number of worms in each swimbladder was recorded and the thickness of the swimbladder wall measured.

The tomograms, radiographs and photographs of the individual eels were arranged into figures with a Microsoft Windows Power Point program. 


\section{RESULTS}

The computerised tomographic topograms of the swimbladder of worm-free eels Anguilla anguilla and of those with Anguillicola crassus infection of varying severity showed perfect agreement with the radiographs of the same fish, but contained less detail than the latter. However, on the 12 to 15 cross-section scans taken of the swimbladders the location of worms in the swimbladder and changes, such as narrowing of the lumen and thickening of the swimbladder wall, were clearly discernible.

The swimbladder of eels revealed as infection-free by X-ray examination (Fig. 1B) also showed a full airfilled lumen in the different segments with computerised tomography (Fig. 1A). On dissection, the swimbladder of these eels proved to be worm-free and thin-walled (wall thickness $<1 \mathrm{~mm}$ ) (Fig. 2). In swimbladders with no radiographic shadow (Figs. 3B \& 5B), no areas containing air were detected by computerised tomography (Figs. 3A \& 5A). On dissection, these swimbladders were assigned to 2 types: (1) airless swimbladders with a markedly thickened wall (Fig. 4); (2) swimbladders with the lumen entirely filled by worms (Fig. 6). In Type 1, the thickness of the swimbladder wall could not be precisely estimated since the absence of contours rendered it indistinguishable from neighbouring organs. In Type 2, dissection revealed only serum and worm debris in the filled swimbladder with no air in the spaces between. The most informative tomographic images (Figs. 7A \& 9A) were of swimbladder lumens that contained only a moderate number of helminths of small or medium size. Here, the shaded cross-sectional areas corresponded to worm positions revealed by X-ray (Figs. 7B \& 9B). Dissection confirmed this, revealing 1 adult worm (Fig. 8), and 1 large and 4 to 5 smaller adult worms (Fig. 10) in the air-filled swimbladder. In the latter cases the thickness of the swimbladder wall was clearly measurable by the CT technique (Figs. 7A \& 9A). In general, the average wall thickness (mean of 3 measurements of each swimbladder) corresponded
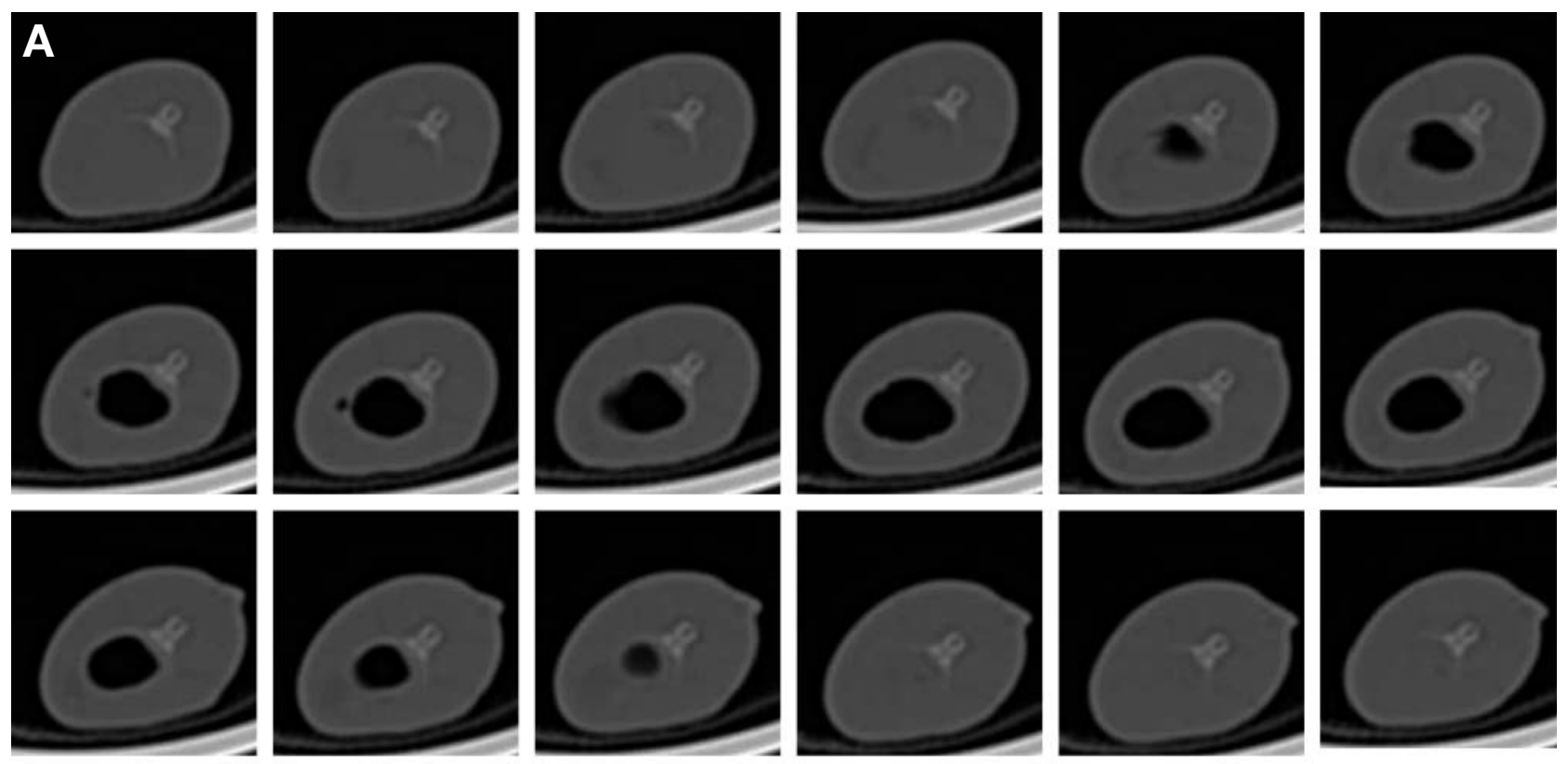

B
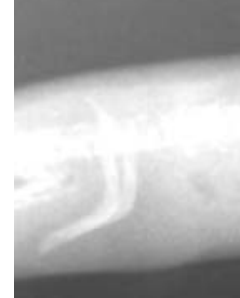

Fig. 1. Anguilla anguilla. (A) Computerised tomograms of swimbladder with no Anguillicola crassus in lumen arranged in caudal direction from oral part of the swimbladder; air-filled swimbladder (ca. $1 \mathrm{~mm}$ thick) is clearly delineated, and is bordered by projections of the spinal vertebrae $(\times 0.74)$. (B) Radiograph of cranial body of same eel with clearly outlined swimbladder $(\times 0.74)$ 

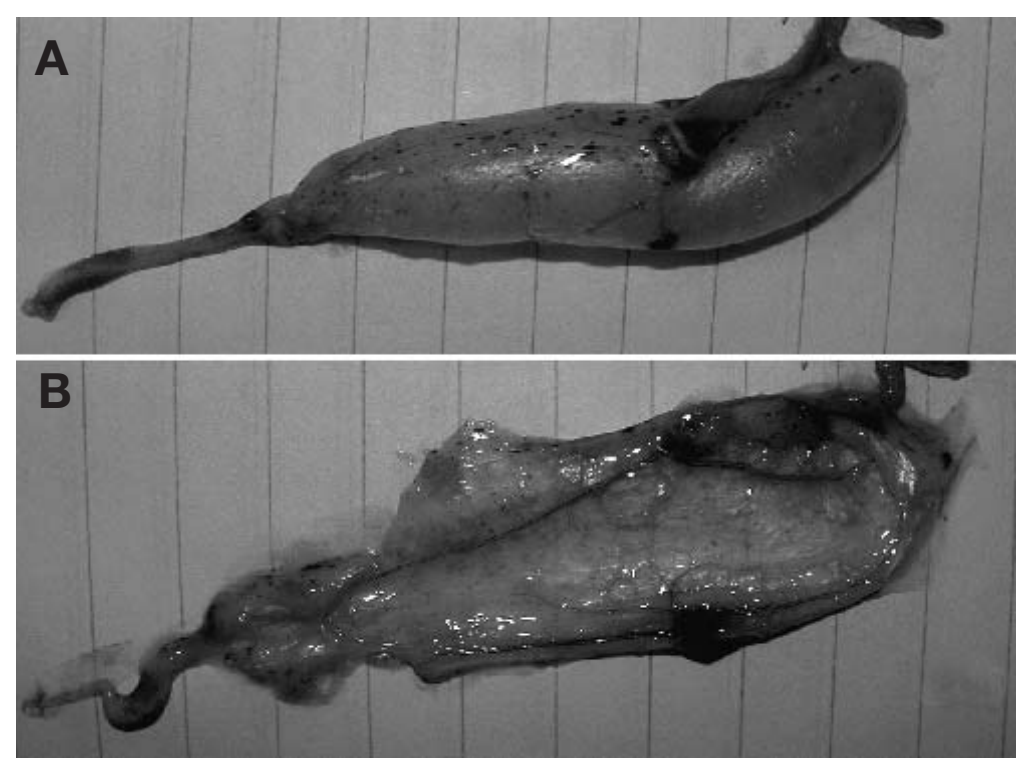

Fig. 2. Anguilla anguilla. (A) Unopened and (B) opened swimbladder dissected from eel in Fig. 1. Lumen is free of Anguillicola crassus; swimbladder wall is thin $(\times 0.9)$ to the wall thickness (approx. $1 \mathrm{~mm}$ ) measured during dissection; however, in 2 cases the wall thickness was 1.8 and $3.3 \mathrm{~mm}$, respectively.

\section{DISCUSSION}

As expected, computerised tomography of eel swimbladders infected by Anguillicola crassus represents a further method of studying the nature of infection by this worm. Tomographic images provide information on the internal structure, air content and wall thickness of the swimbladder and on the number of worms present. For less severely affected swimbladders (i.e.) not completely filled with worms this method provides data on the shape and wall thickness of the swimbladder and on the location of worms in its lumen. When the swimbladder con-
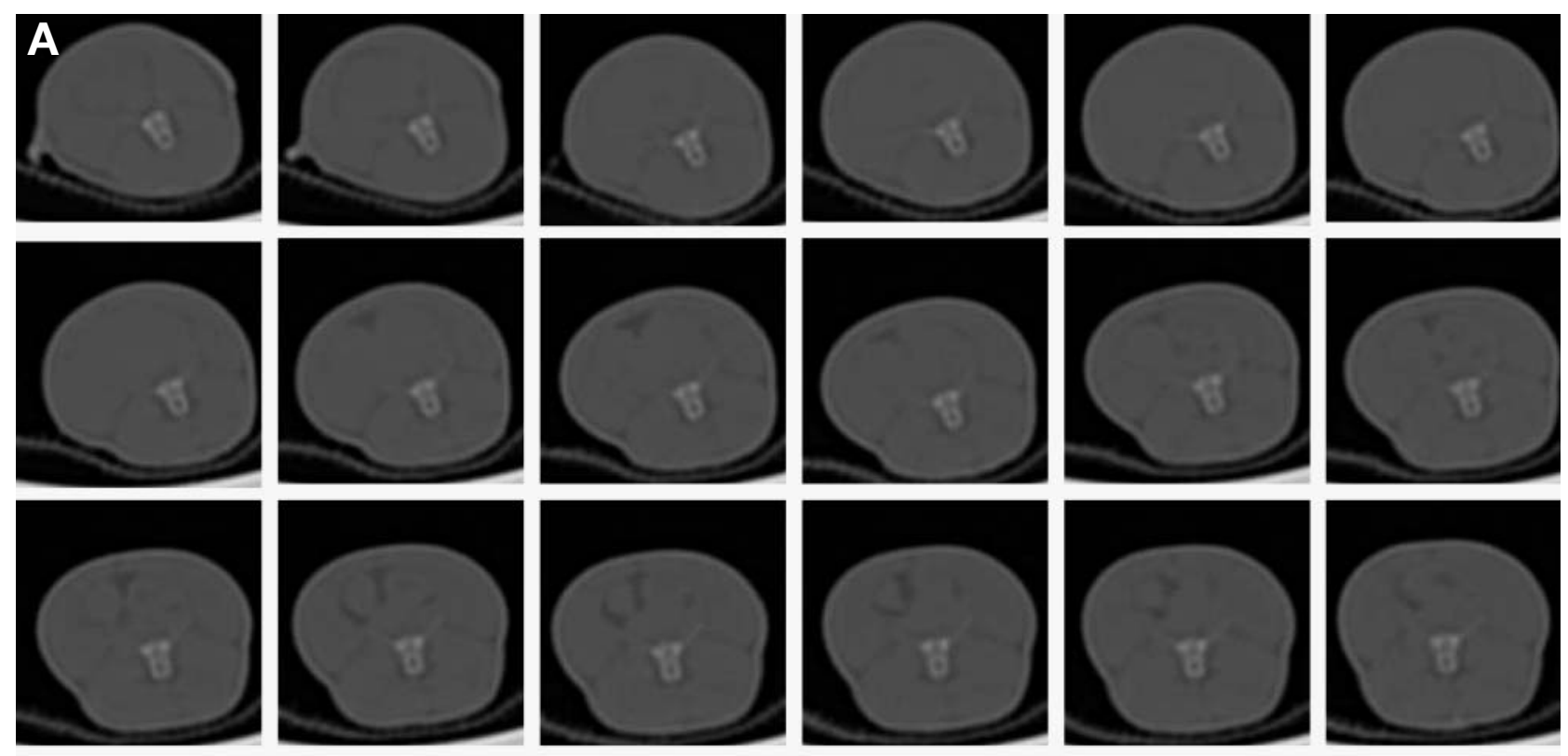

B
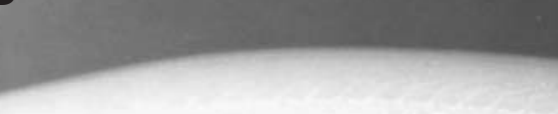


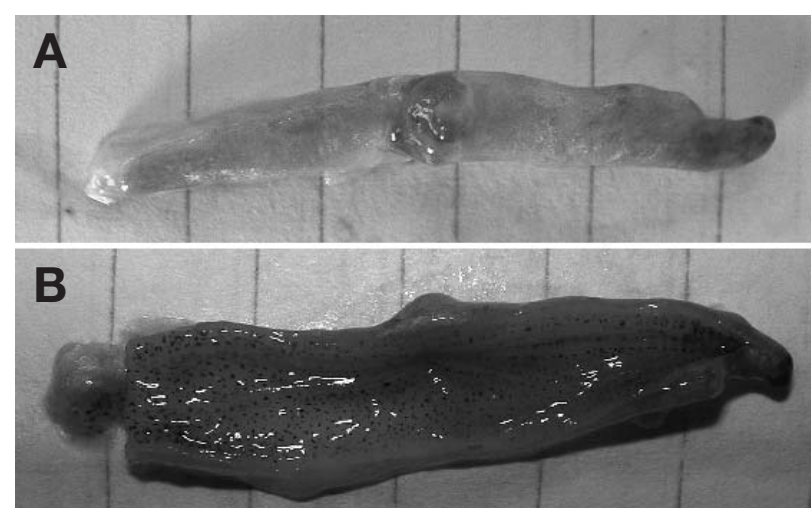

Fig. 4. Anguilla anguilla. (A) Unopened and (B) opened tubelike, thick-walled swimbladder dissected from eel in Fig. 3. No Anguillicola crassus are present in airless lumen; swimbladder wall is fibrous and $>3 \mathrm{~mm}$ thick $(\times 1.05)$

tains air, the contours of worms in the bladder are clearly discernible and the wall thickness of the swimbladder can also be easily measured, although the physical resolution (approx. $1 \mathrm{~mm}$ ) and the characteristic swimbladder wall thickness values were similar. Tomographic measurement of the average wall thickness of the swimbladder (3 times in 1 plane) yielded reliable data that corresponded to those obtained by direct measurement during dissection.

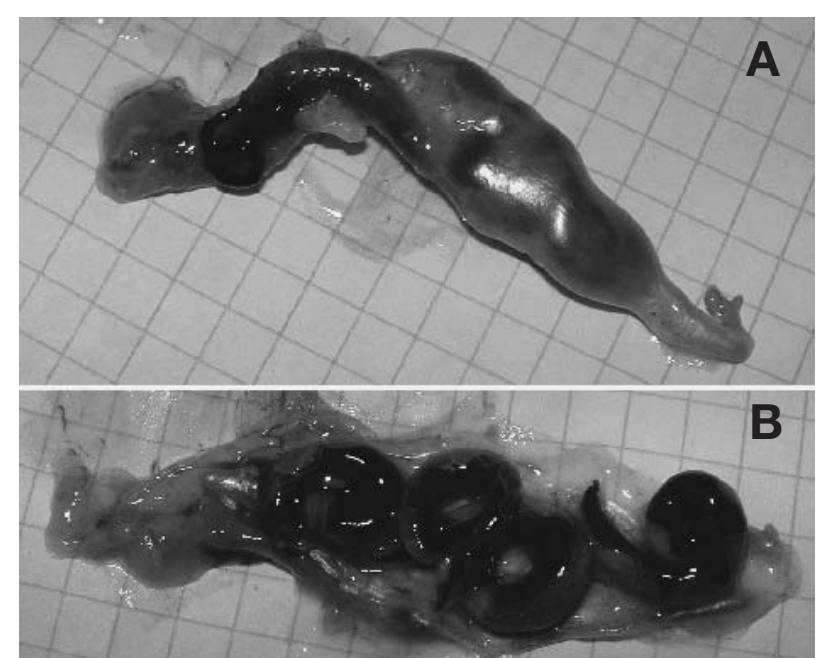

Fig. 6. Anguilla anguilla. (A) Swimbladder from eel in Fig. 5 tightly packed with worms, with 2 smaller worms protruding from pneumatic duct that opens from swimbladder $(\times 0.84)$. (B) Opened swimbladder; the lumen of relatively thin-walled swimbladder contains a few large, egg-filled worms and some smaller specimens $(\times 0.84)$

However, although computerised tomography reveals severe cases of infection, i.e. when the swimbladder is completely filled with worms or contains no air as a result of wall-thickening, it does not provide data on
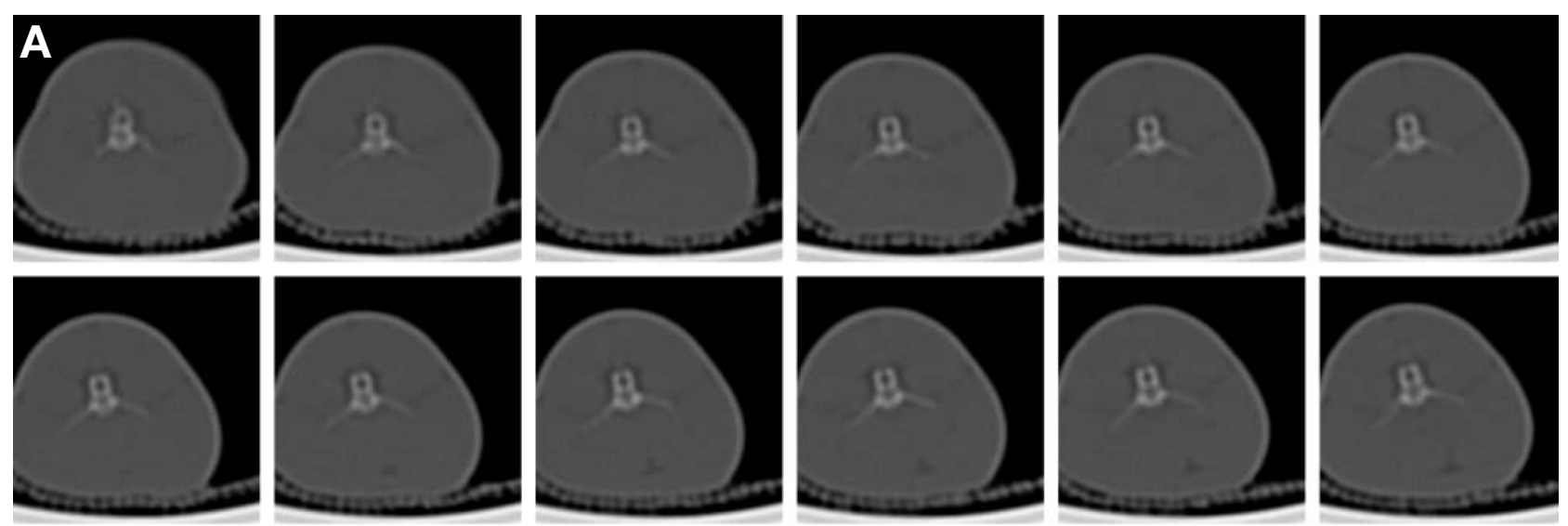

\section{B}

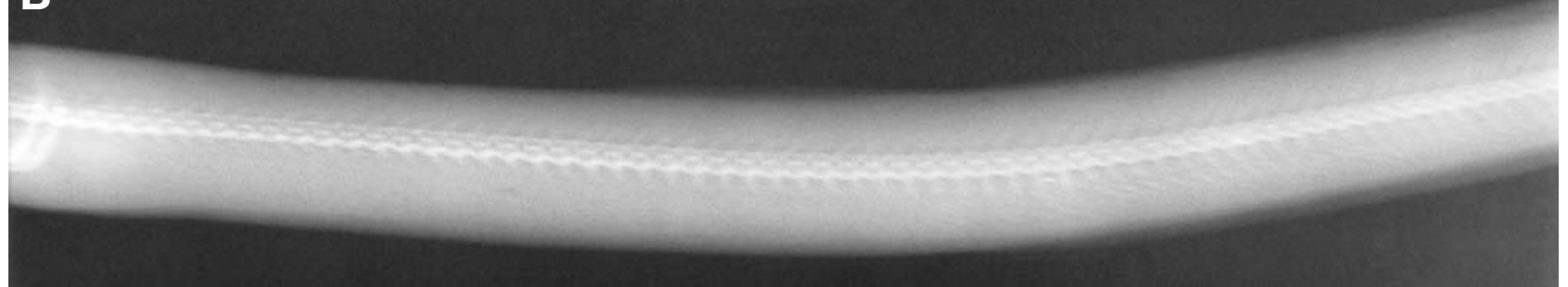

Fig. 5 Anguilla anguilla. (A) Computerised tomogram of swimbladder with lumen completely filled with worms; swimbladder is not visible $(\times 0.71)$. (B) Radiograph of cranial body of same eel; no radiographic shadow indicating swimbladder is visible $(\times 0.61)$ 


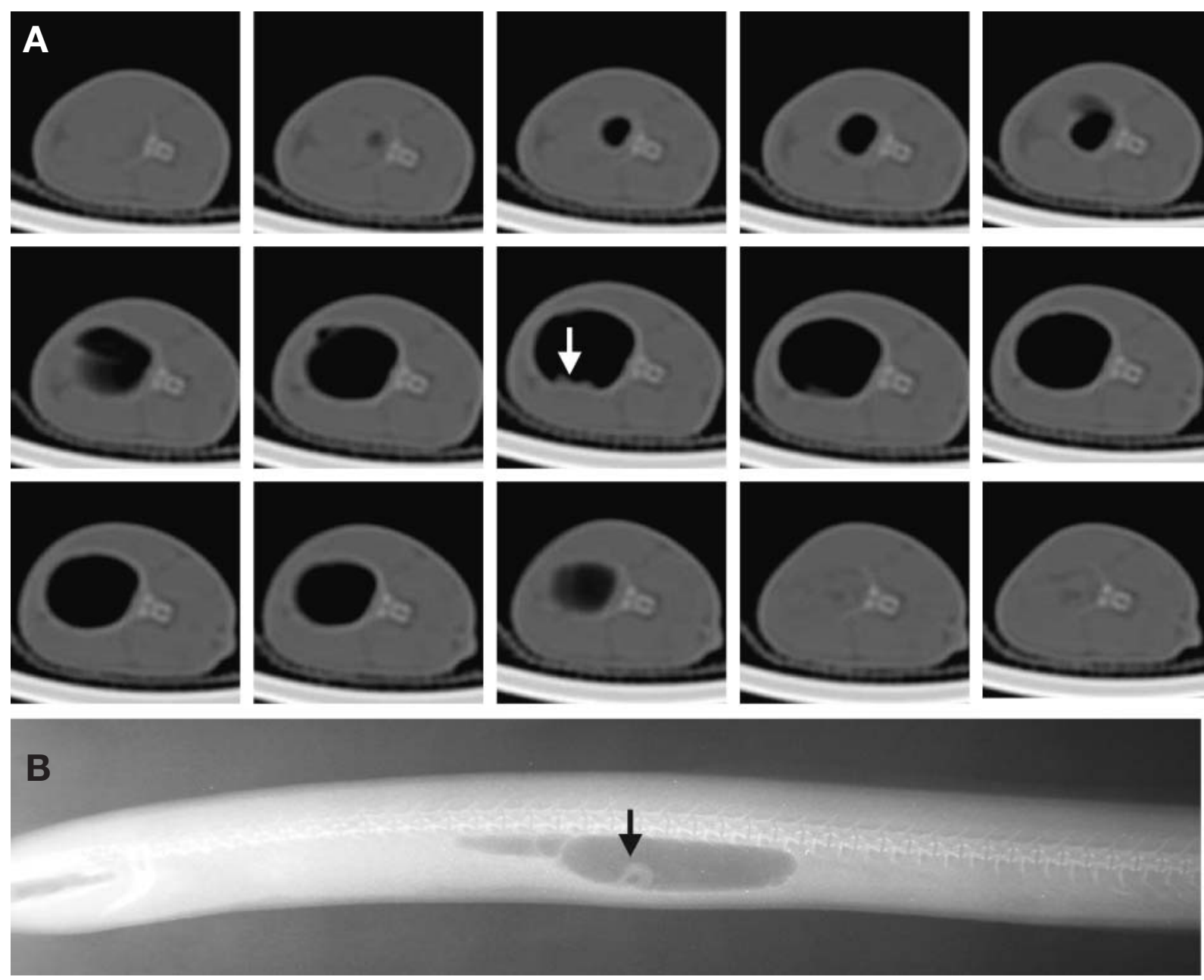

Fig. 7. Anguilla anguilla. (A) Computerised tomogram of swimbladder containing 1 adult worm; swimbladder is clearly visible, and is bordered by vertebrae; Segment 8 contains clearly discernible specimen of Anguillicola crassus (arrow) ( $\times 0.77$ ).

(B) Radiograph of same eel with distinct radiographic shadow of coiled worm (arrow) $(\times 0.54)$

the number and location of the worms or on the thickness of the swimbladder wall. Although computerised tomography provides more detailed data for the diagnosis of helminth infection and swimbladder damage than radiography, its practical applicability does not exceed that of the much cheaper and simpler radiodiagnostic procedure. Therefore, computerised tomography can be recommended for use only as a complementary method, primarily for research purposes.
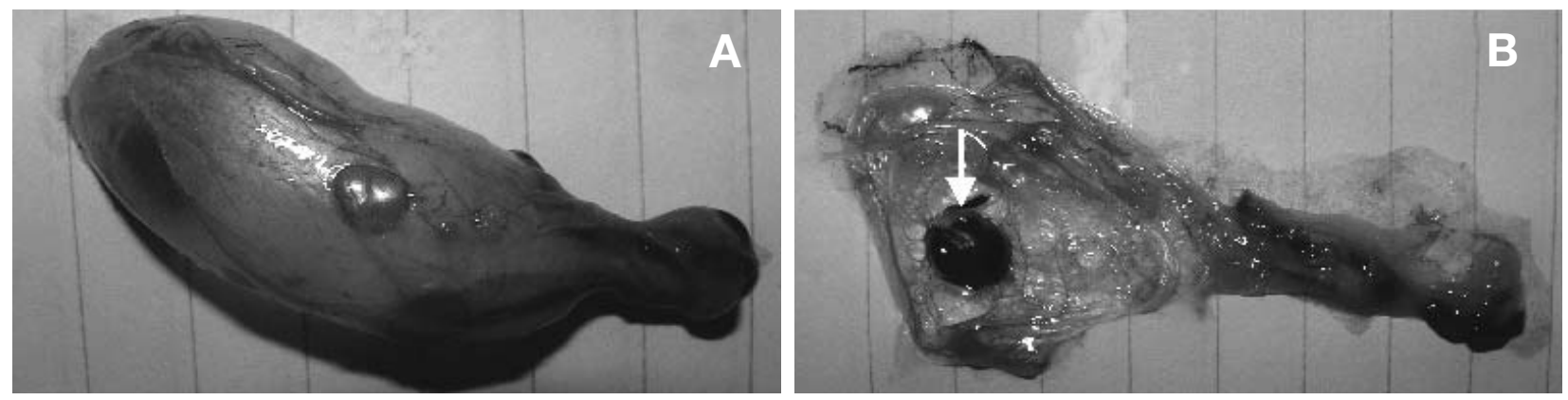

Fig. 8. Anguilla anguilla. (A) Thin-walled swimbladder dissected from eel in Fig. 7. Opened swimbladder; lumen of relatively thin-walled swimbladder contains well-developed Anguillicola crassus specimen (arrow) $(\times 1)$ 

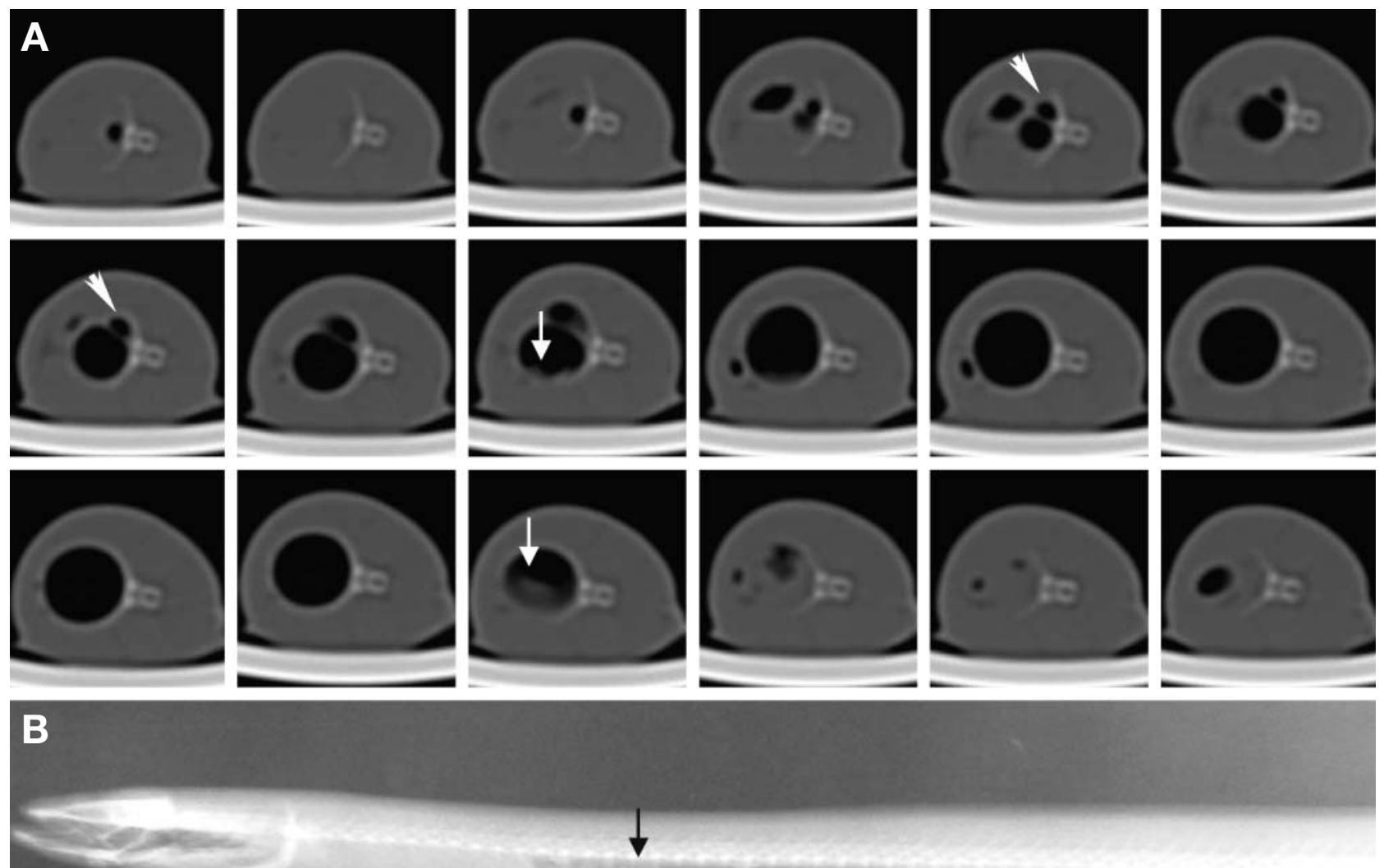

Fig. 9. Anguilla anguilla. (A) Computerised tomogram of swimbladder containing moderate number of worms. Swimbladder and pneumatic duct (arrowheads) are clearly visible, and is bordered by vertebrae; Anguillicola crassus specimens (arrows) are clearly visible in some segments. In Segments 2 and 15 to 17, swimbladder shadow is not visible because space is occupied by worms ( $\times 0.71$ ). (B) Radiograph of cranial body of same eel; radiographic shadow (arrow) of worms is clearly visible in cranial part of swimbladder under the vertebrae $(\times 0.43)$

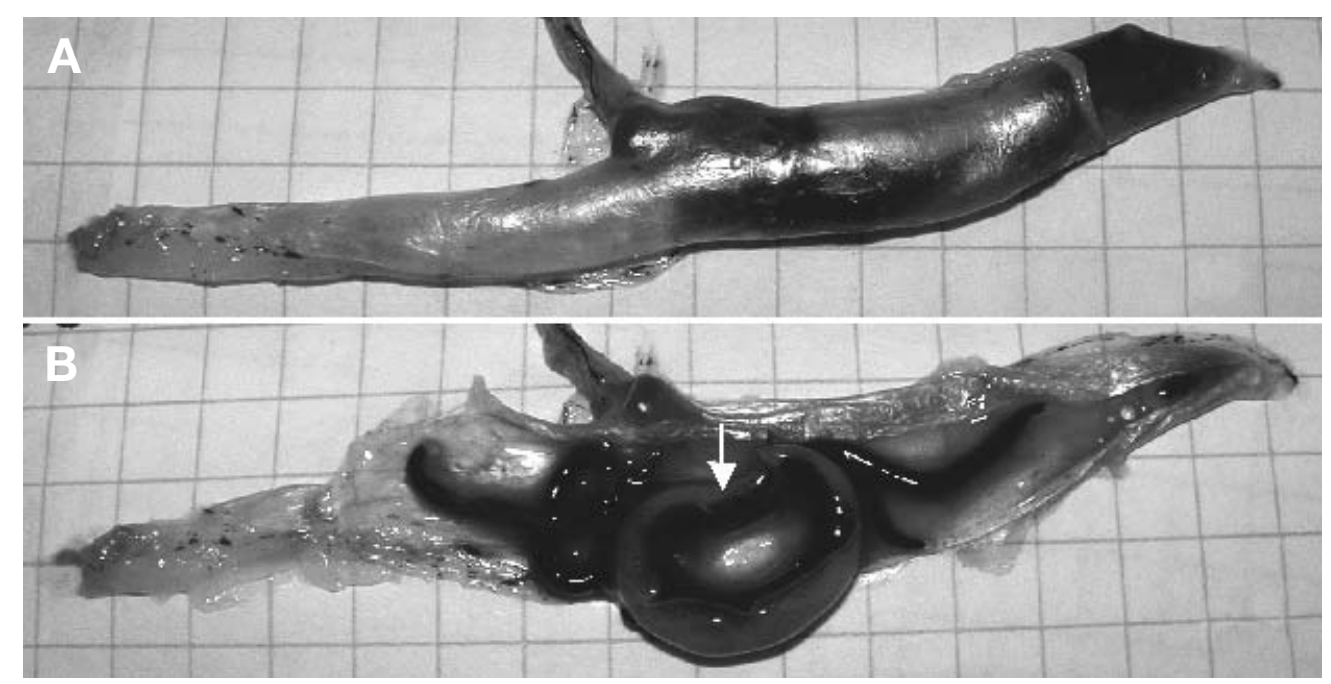

Fig. 10. Anguilla anguilla. (A) Swimbladder dissected from eel in Fig. 9; contours of worms are clearly visible through transparent, thin swimbladder wall. (B) Opened swimbladder; lumen of relatively thin-walled swimbladder contains 1 large and a few smaller Anguillicola crassus specimens $(\times 1.44)$ 
Acknowledgements. The authors thank Orsolya Rácz, Györgyi Ostoros Pataki, Mrs. Józsefné Kampó, András Specziár, István Báthory and Géza Dobos for their valuable help during this work. Financial support was provided by research contracts EU Q5RS-2001-01836 (EELREP) and the Hungarian Scientific Research Fund (OTKA) project no. T 031755.

\section{LITERATURE CITED}

Bakal RS, Love NE, Lewbart GA, Berry CR (1998) Imaging a spinal fracture in a kohaku koi (Cyprinus carpio): techniques and case history report. Vet Radiol Ultrasound 39: 318-321

Barus V (1995) First record of Anguillicola crassus (Nematoda) in the Morava River drainage basin. Helminthologia 32:89

Barus V, Prokes M (1996) Length-weight relations of uninfected and infected eels (Anguilla anguilla) by Anguillicola crassus (Nematoda). Folia Zool 45:183-189

Beregi A, Molnár K, Békési L, Székely C (1998) Radiodiagnostic method for studying swimbladder inflammation caused by Anguillicola crassus (Nematoda: Dracunculoidea). Dis Aquat Org 34:155-160

Beregi A, Székely C, Békési L, Szabó J, Molnár V, Molnár K (2001) Radiodiagnostic examination of the swimbladder of some fish species. Acta Vet Hung 49:87-98

Böttcher K, Böttcher M (2000) Röntgendiagnostik bei Fischen: Röntgenanatomie des Karpfens. Kleintierpraxis 45:351-358

Garland MR, Lawler LP, Whitaker BR, Walker ID, Corl FM, Fish EK (2002) Modern CT applications in veterinary medicine. Radiographics 22:55-62

Gore RM, Yaghmai V, Newmark GM, Berlin JW, Miller FH (2002) Imaging benign and malignant disease of the gallbladder. Radiol Clin N Am 40:1307-1323

Kilani T, El Hammami S (2002) Pulmonary hydatid and other lung parasitic infections. Curr Opin Pulm Med 8:218-223

Laato M, Ekfors T, Alanen A, Rajala P, Nurmi M (2001) Leiomyoma of the urinary bladder. Ann Chir Gynaecol 90(Suppl 215):55-57

Liu YH, Wang XG, Chen YT (1993) Computer tomography of liver in alveolar echinococcosis treated with albendazole. Trans R Soc Trop Med Hyg 87:319-321

Love NE, Lewbart GA (1997) Pet fish radiography: technique and case history reports. Vet Radiol Ultrasound 38:24-29

Minguetti G, Ferreira MV (1983) Computed tomography in neurocysticercosis. J Neurol Neurosurg Psychiatry 46: 936-942

Editorial responsibility: Wolfgang Körting,

Hannover, Germany
Molnár K (1993) Effect of decreased oxygen content on eels (Anguilla anguilla) infected by Anguillicola crassus (Nematoda: Dracunculoidea). Acta Vet Hung 41:349-360

Molnár K (1994) Formation of parasitic nodules in the swimbladder and in the intestinal walls of the eels Anguilla anguilla due to infections with larval stages of Anguillicola crassus. Dis Aquat Org 20:163-170

Molnár K, Székely C, Baska F (1991) Mass mortality of eel in Lake Balaton due to Anguillicola crassus infection. Bull Eur Assoc Fish Pathol 11:211

Molnár K, Baska F, Csaba G, Glávits R, Székely C (1993) Pathological and histopathological studies of the swimbladder of eel Anguilla anguilla infected by Anguillicola crassus (Nematoda: Dracuncoloidea). Dis Aquat Org 15: $41-50$

Moravec F (1992) Spreading of the nematode Anguillicola crassus (Dracuncoloidea) among eel populations in Europe. Folia Parasitol (Ceske Budejovice) 39:247-248

Palme CE, Lowinger D, Petersen AJ (1999) Fish bones at the cricopharyngeus: a comparison of plain-film radiology and computerised tomography. Laryngoscope 109:1955-1958

Pavlidis TE, Papaziogas BT, Koutelidakis IM, Papaziogas TB (2002) Abdominal wall sinus due to impacting gallstone during laparoscopic cholecystectomy: an unusual complication. Surg Endosc 16:360

Ramos G, Orduna A, Garcia-Yuste M (2001) Hydatid cyst of the lung: diagnosis and treatment. World J Surg 25:46-57

Rickes S, Ocran K (2002) Images in clinical medicine: porcelain gallbladder. N Engl J Med 346:e4

Sprengel G, Lüchtenberg H (1991) Infection by endoparasites reduces maximum swimming speed of European smelt Osmerus eperlanus and European eel Anguilla anguilla. Dis Aquat Org 11:31-35

Székely C, Láng M, Csaba G (1991) First occurrence of Anguillicola crassus in Hungary. Bull Eur Ass Fish Pathol 11:162-163

van Banning P, Haenen OLM (1990) Effect of the swimbladder nematode Anguillicola crassus in wild and farmed eel, Anguilla anguilla. In: Perkins FO, Cheng TC (eds) Pathology in marine science. Academic Press, New York, p 317-330

Weisse C, Weber ES, Matzkin Z, Klide A (2002) Surgical removal of a seminoma from black sea bass. J Am Vet Med Assoc 221:280-283

Würtz J, Taraschewski H (2000) Histopathological changes in the swimbladder wall of the European eel Anguilla anguilla due to infection with Anguillicola crassus. Dis Aquat Org 39:121-134

Submitted: April 14, 2003; Accepted: August 15, 2003

Proofs received from author(s): February 2, 2004 